\title{
Highly prevalent BRAF V600E and low-frequency TERT promoter mutations underlie papillary thyroid carcinoma in Koreans
}

\author{
Sue Youn Kim ${ }^{1}$, Taeeun $\mathrm{Kim}^{2}$, Kwangsoon $\mathrm{Kim}^{3}$, Ja Seong Bae ${ }^{3}$, Jeong Soo Kim³ ${ }^{3}$ Chan Kwon Jung ${ }^{1,4}$ \\ 1Department of Hospital Pathology, College of Medicine, The Catholic University of Korea, Seoul; \\ 2Molecular Pathology Unit, Pathology Laboratory, Seoul St. Mary's Hospital, College of Medicine, The Catholic University of Korea, Seoul; \\ ${ }^{3}$ Department of Surgery, College of Medicine, The Catholic University of Korea, Seoul; \\ ${ }^{4}$ Cancer Research Institute, College of Medicine, The Catholic University of Korea, Seoul, Korea
}

\begin{abstract}
Background: The presence of telomerase reverse transcriptase (TERT) promoter mutations have been associated with a poor prognosis in patients with papillary thyroid carcinomas (PTC). The frequency of TERT promoter mutations varies widely depending on the population and the nature of the study. Methods: Data were prospectively collected in 724 consecutive patients who underwent thyroidectomy for PTC from 2018 to 2019. Molecular testing for BRAF V600E and TERT promoter mutations was performed in all cases. Results: TERT promoter alterations in two hotspots (C228T and C250T) and C216T were found in $16(2.2 \%)$ and $4(0.6 \%)$ of all PTCs, respectively. The hotspot mutations were significantly associated with older age at diagnosis, larger tumor size, extrathyroidal extension, higher pathologic T category, lateral lymph node metastasis, and higher American Thyroid Association recurrence risk. The patients with C216T variant were younger and had a lower American Thyroid Association recurrence risk than those with hotspot mutations. Concurrent BRAF V600E was found in 19 of 20 cases with TERT promoter mutations. Of 518 microcarcinomas measuring $\leq 1.0 \mathrm{~cm}$ in size, hotspot mutations and C216T variants were detected in five (1.0\%) and three (0.6\%) cases, respectively. Conclusions: Our study indicates a low frequency of TERT promoter mutations in Korean patients with PTC and supports previous findings that TERT promoter mutations are more common in older patients with unfavorable clinicopathologic features and BRAF V600E. TERT promoter mutations in patients with microcarcinoma are uncommon and may have a limited role in risk stratification. The C216T variant seems to have no clinicopathologic effect on PTC.
\end{abstract}

Key Words: Papillary thyroid carcinoma; TERT promoter; BRAF; Molecular typing; Mutation rate

Received: March 31, 2020 Revised: May 4, 2020 Accepted: May 12, 2020

Corresponding Author: Chan Kwon Jung, MD, PhD, Department of Pathology, Seoul St. Mary's Hospital, College of Medicine, The Catholic University of Korea, 222 Banpo-daero, Seocho-gu, Seoul 06591, Korea

Tel: +82-2-2258-1622, Fax: +82-2-2258-1627, E-mail: ckjung@catholic.ac.kr

The incidence of thyroid cancer has dramatically increased over the past several decades [1,2]. The highest incidence of thyroid cancer in the world has been observed in Korea [3,4]. The increase in the incidence of thyroid cancer was responsible for the increase in papillary thyroid carcinoma (PTC), which accounts for over $95 \%$ of all thyroid cancer cases in Korea [3,5,6]. Despite the increased incidence of thyroid cancer, the thyroid cancer mortality rate has not changed significantly over the last three decades [3,5]. A multicenter cohort study reported a disease-specific 10-year survival rate of $98 \%$ in Korean patients with welldifferentiated thyroid carcinoma [6].

Independent prognostic factors related to survival in patients with PTC include elements of cancer staging, such as patient age at diagnosis, tumor size, extensive extrathyroidal extension, and distant metastasis [7]. There have been many studies demonstrating the prognostic value of molecular markers for tumor recurrence and survival. Telomerase reverse transcriptase (TERT) promoter mutation is one of the most evident molecular factors related to poor prognosis of patients with PTC [8-11]. The cancer-specific TERT promoter mutations occur in two mutually exclusive hotspots in chromosome 5, g.1 $295228 \mathrm{C}>\mathrm{T}$ (C228T) and g.1 $295250 \mathrm{C}>\mathrm{T}(\mathrm{C} 250 \mathrm{~T})$ which correspond to $124 \mathrm{bp}$ (c. $-124 \mathrm{C}>\mathrm{T}$ ) and $146 \mathrm{bp}$ (c. $-146 \mathrm{C}>\mathrm{T}$ ), upstream from the translation start codon of the TERT gene promoter sequence [10-16]. The pooled prevalence of TERT promoter mutations in PTC was $11.3 \%$ (95\% confidence interval, 9.3 to 13.5 ) in a 
previous meta-analysis of 13 studies [14]. However, the retrospective data may overestimate the mutation frequency because of potential patient selection bias. Patients with microcarcino$\mathrm{ma} \leq 1.0 \mathrm{~cm}$ were more easily excluded from the molecular studies [8-10,15,17-19]. Furthermore, old archival paraffin blocks may have suboptimal DNA quality that results in molecular test failures and analytical errors.

The BRAF V600E mutation is the most common genetic alteration in PTC and remains controversial as an independent prognostic factor [7]. The coexistence of BRAF V600E and TERT promoter mutations, however, could more accurately indicate the highest mortality risk for patients with PTC $[8,19]$.

The present study aimed to evaluate the real-world frequency of TERT promoter mutations in prospectively-collected consecutive cases of PTC and assess the relationship between TERT promoter mutations and clinicopathological features in Korean patients with PTC and a high frequency of $B R A F$ V600E mutations.

\section{MATERIALS AND METHODS}

\section{Patients}

We reviewed the prospectively collected data from 724 consecutive patients who underwent thyroidectomy for PTC and molecular testing at Seoul St. Mary's Hospital of the Catholic University of Korea from 2018 to 2019. Molecular tests for BRAF and TERT promoter mutations were performed in all patients who agreed to allow molecular analysis of their surgical specimens. In cases of multifocal PTCs, the largest tumor was defined as the primary lesion and was chosen for evaluation. The histologic variants of PTC were classified following the diagnostic criteria and terminology of the World Health Organization [7]. The tall cell variant was defined using $30 \%$ of tall cell area as a criterion. The PTCs were further classified as classic PTC with tall cell features if it harbored between 10\%-30\% tall cells and as classic PTC if it contained less than $10 \%$ of tall cell area and any well-formed papillae. Cancer staging was done using the 8th edition of the American Joint Committee on Cancer (AJCC) staging system [20]. Minimal extrathyroidal extension was defined as extrathyroidal invasion that was restricted to the perithyroidal soft tissues detected only on microscopic examination (including microscopic strap muscle invasion). When strap muscle invasion was found on preoperative imaging and/or at the time of surgery, the case was considered as gross extrathyroidal extension. Risk stratification of patients for tumor recurrence was done using the 2015 American Thyroid Association (ATA) guidelines [21].

\section{Mutational analyses for TERT promoter and BRAF V600E mutations}

Genomic DNA was extracted from $10 \mu \mathrm{m}$-thick formalinfixed paraffin-embedded (FFPE) tissue blocks using a Maxwell 16 FFPE Tissue LEV Purification Kit (Promega, Fitchburg, WI, USA). Tumor areas were manually dissected with a scalpel under a microscope.

The TERT promoter was amplified using the nested polymerase chain reaction (PCR) method. The first-round 235-bp PCR amplicon was amplified using forward 5'-AGTGGATTCGCGGGCACAGA-3' and reverse 5'-CAGCGCTGCCTGAA ACTC-3' primers. Then, the second-round 163-bp PCR amplicon was amplified using forward 5'-GTCCTGCCCCTTCACCTT$3^{\prime}$ and reverse 5'-CAGCGCTGCCTGAAACTC-3' primers. Bidirectional Sanger sequencing was performed in both directions using the same primers that were used for the second-round PCR. BRAF V600E mutation was analyzed using the real-time PCR clamping technology of PNAClampTM BRAF kit (Panagene, Daejeon, Korea) [22]. Each test had a positive control of mutation-holding human genomic DNA and a negative control of distilled water.

\section{Statistical analysis}

Categorical variables were analyzed using the Pearson's chisquare, Fisher exact test, or linear-by-linear association when appropriate. Continuous variables were compared using the Student's t-test or Mann-Whitney test when appropriate. The statistical significance threshold was defined as a p-value less than 0.05. All statistical analyses were done using SPSS Statistics program, ver. 21.0 (IBM Corp., Armonk, NY, USA).

\section{RESULTS}

\section{Demographic and clinicopathologic characteristics}

Table 1 summarizes the baseline clinicopathologic characteristics of the 724 patients with PTC. The median age of the patients at the time of diagnosis was 46 years (interquartile range [IQR], 36 to 56 years). The female to male ratio was 2.7:1. The median tumor size was $0.7 \mathrm{~cm}$ (IQR, 0.5 to $1.1 \mathrm{~cm}$ ). The proportion of microcarcinomas ( $\leq 1.0 \mathrm{~cm}$ in size) was $71.5 \%$ (518/724). Lobectomy was done in 504 (69.6\%) and total thyroidectomy in 191 patients (26.4\%). The numbers of patients with minimal and gross extrathyroidal extension were 405 (55.9\%) and $41(5.7 \%)$, respectively. Cervical lymph node metastases were found in 409 patients $(56.5 \%)$. 
Table 1. Baseline characteristics

\begin{tabular}{|c|c|}
\hline Characteristic & $\begin{array}{l}\text { No. }(\%) \\
(n=724)\end{array}$ \\
\hline Age at diagnosis (yr) & $45.9 \pm 13.0$ \\
\hline$<55$ & $531(73.3)$ \\
\hline$\geq 55$ & $193(26.7)$ \\
\hline \multicolumn{2}{|l|}{ Sex } \\
\hline Female & $528(72.9)$ \\
\hline Male & $196(27.1)$ \\
\hline \multicolumn{2}{|l|}{ Tumor size $(\mathrm{cm})$} \\
\hline$\leq 1.0$ & $518(71.5)$ \\
\hline$>1.0$ & $206(28.5)$ \\
\hline \multicolumn{2}{|l|}{ Surgical procedure } \\
\hline Lobectomy & $504(69.6)$ \\
\hline Total thyroidectomy & $191(26.4)$ \\
\hline Isthmusectomy & $29(4.0)$ \\
\hline \multicolumn{2}{|l|}{ Histologic types } \\
\hline Classic & $490(67.7)$ \\
\hline Classic with tall cell features & $83(11.5)$ \\
\hline Classic encapsulated & $46(6.4)$ \\
\hline Tall cell variant & $49(6.8)$ \\
\hline Warthin-like variant & $15(2.1)$ \\
\hline Infiltrative follicular variant & $10(1.4)$ \\
\hline Invasive encapsulated follicular variant & $6(0.8)$ \\
\hline Diffuse sclerosing variant & $8(1.1)$ \\
\hline Oncocytic variant & $8(1.1)$ \\
\hline Solid variant & $5(0.7)$ \\
\hline Hobnail variant & $3(0.4)$ \\
\hline Cribriform-morular variant & $1(0.1)$ \\
\hline \multicolumn{2}{|l|}{ Extrathyroidal extension ${ }^{\mathrm{a}}$} \\
\hline Absent & $278(38.4)$ \\
\hline Minimal (microscopic) & $405(55.9)$ \\
\hline Gross (strap muscle invasion, pT3b) & $30(4.1)$ \\
\hline $\begin{array}{l}\text { Gross (tracheal, esophageal or recurrent laryngeal nerve } \\
\text { invasion, pT4a) }\end{array}$ & $11(1.5)$ \\
\hline \multicolumn{2}{|l|}{ Pathologic T category ${ }^{a}$} \\
\hline pT1 & $651(89.9)$ \\
\hline pT2 & $30(4.1)$ \\
\hline pT3 & $32(4.4)$ \\
\hline pT4 & $11(1.5)$ \\
\hline \multicolumn{2}{|l|}{ Lymph node metastasis ${ }^{a}$} \\
\hline Absent (pNO) & $315(43.5)$ \\
\hline Central lymph node (pN1a) & $346(47.8)$ \\
\hline Lateral lymph node (pN1b) & $63(8.7)$ \\
\hline \multicolumn{2}{|l|}{ ATA recurrence risk } \\
\hline Low risk & $241(33.3)$ \\
\hline Intermediate risk & $358(49.4)$ \\
\hline High risk & $125(17.3)$ \\
\hline \multicolumn{2}{|l|}{ AJCC cancer staging ${ }^{a}$} \\
\hline Stage I & $623(86.0)$ \\
\hline Stage II & $98(13.5)$ \\
\hline Stage III & $3(0.4)$ \\
\hline Stage IV & 0 \\
\hline
\end{tabular}

\begin{tabular}{lc}
\hline Characteristic & $\begin{array}{c}\text { No. }(\%) \\
(\mathrm{n}=724)\end{array}$ \\
\hline BRAF V600E mutation & $108(14.9)$ \\
Absent & $616(85.1)$ \\
Present & \\
TERT promoter mutation & $704(97.2)$ \\
Wild & $14(1.9)$ \\
C228T mutation & $2(0.3)$ \\
C250T mutation & $4(0.6)$ \\
C216T variant & \\
\hline
\end{tabular}

ATA, American Thyroid Association; TERT, telomerase reverse transcriptase. aAll TNM categorization and staging were done according to the 8th American Joint Committee on Cancer (AJCC).

\section{Frequency of TERT promoter and BRAF V600E mutations}

Hotspot-point mutations (C228T and C250T) in the TERT promoter were found in $16(2.2 \%)$ patients: 14 with C228T and two with C250T (Table 2, Fig. 1). Four cases had the TERT promoter variant of g.1 $295216 \mathrm{C}>\mathrm{T}$ (c. $-112 \mathrm{C}>\mathrm{T}$ ) (hereafter C216T) (Fig. 1). The BRAF V600E mutation was found in $616(85.1 \%)$ patients. Of 20 PTCs with TERT promoter aberrations, 19 had coexisting BRAF V600E (Table 3, Fig. 2). Fig. 2 summarizes the distribution of histologic variants of PTC and mutational profiles according to the variants. There was no correlation between TERT promoter mutations and histologic variants.

\section{Clinicopathologic features of patients with TERT promoter mutation}

Hotspot mutations in the TERT promoter were significantly associated with age $\geq 55$ years $(\mathrm{p}<.001)$, tumor size $>1.0 \mathrm{~cm}(\mathrm{p}=$ .001 ), extrathyroidal extension $(\mathrm{p}=.032)$, lateral lymph node metastasis $(\mathrm{p}=.041)$, and higher ATA recurrence risk $(\mathrm{p}<.001)$ (Table 2). Compared with patients with hotspot mutations, those with $\mathrm{C} 216 \mathrm{~T}$ variant were younger $(\mathrm{p}=.032)$ and had a lower rate of high ATA recurrence risk $(\mathrm{p}=.014)$. There were no significant differences in the clinicopathologic features between the patients with wild-type TERT promoter mutations and those with C216T variant of the TERT promoter (Table 2). Table 3 shows the detailed clinicopathologic features of the patients with a TERT promoter mutation.

\section{DISCUSSION}

The strength of this study stems from the prospectively collected data encompassing all consecutive patients treated for PTC with thyroid surgery. In our study, almost three-quarters of patients with PTC underwent thyroid surgery before the age of 55 years $(73.3 \%)$ and had microcarcinomas $(71.5 \%)$. Gross 
Table 2. Association between TERT promoter alterations and clinicopathologic features in 724 consecutive patients with papillary thyroid carcinoma

\begin{tabular}{|c|c|c|c|c|c|c|}
\hline \multirow{2}{*}{ Variable } & \multicolumn{3}{|c|}{ TERT promoter alteration, $\mathrm{n}(\%)$} & \multicolumn{3}{|c|}{$p$-value } \\
\hline & Wild-type (A) & С228T, C250T (B) & $\mathrm{C} 216 \mathrm{~T}(\mathrm{C})$ & A vs. B & B vs. C & A vs. C \\
\hline Age at diagnosis (yr) & & & & $<.001$ & .032 & $>.99$ \\
\hline$<55$ & $526(99.1)$ & $2(0.4)$ & $3(0.6)$ & & & \\
\hline$\geq 55$ & $178(92.2)$ & $14(7.3)$ & $1(0.5)$ & & & \\
\hline Sex & & & & .776 & .587 & .295 \\
\hline Female & $515(97.5)$ & $11(2.1)$ & $2(0.4)$ & & & \\
\hline Male & $189(96.4)$ & $5(2.6)$ & $2(1.0)$ & & & \\
\hline Tumor size $(\mathrm{cm})$ & & & & .001 & .255 & $>.99$ \\
\hline$\leq 1.0$ & $510(98.5)$ & $5(1.0)$ & $3(0.6)$ & & & \\
\hline$>1.0$ & $194(94.2)$ & $11(5.3)$ & $1(0.5)$ & & & \\
\hline Histologic variant & & & & .313 & .214 & .405 \\
\hline Classic $^{\mathrm{a}}$ & $603(97.4)$ & $12(1.9)$ & $4(0.6)$ & & & \\
\hline Classic with TCF & $78(94.0)$ & $5(6.0)$ & 0 & & & \\
\hline Tall cell variant & $46(93.9)$ & $3(6.1)$ & 0 & & & \\
\hline Follicular variant ${ }^{b}$ & $16(100)$ & 0 & 0 & & & \\
\hline Other ${ }^{c}$ & $39(97.5)$ & $1(2.5)$ & 0 & & & \\
\hline Extrathyroidal extension & & & & .032 & .162 & .645 \\
\hline Absent & $274(98.6)$ & $2(0.7)$ & $2(0.7)$ & & & \\
\hline Present ${ }^{d}$ & $430(96.4)$ & $14(3.1)$ & $2(0.4)$ & & & \\
\hline Pathologic T category & & & & $<.001$ & .267 & $>.99$ \\
\hline pT1-2 & $667(97.9)$ & $10(1.5)$ & $4(0.6)$ & & & \\
\hline рT3-4 & $37(86.0)$ & $6(14.0)$ & 0 & & & \\
\hline Pathologic $N$ category & & & & .297 & .619 & .322 \\
\hline pNO & $304(96.2)$ & $9(2.8)$ & $3(0.9)$ & & & \\
\hline $\mathrm{pN} 1$ & $400(98.0)$ & $7(1.7)$ & $1(0.2)$ & & & \\
\hline Lateral lymph node metastasis & & & & .041 & $>.99$ & .294 \\
\hline Absent & $646(97.7)$ & $12(1.8)$ & $3(0.5)$ & & & \\
\hline Present & $58(92.1)$ & $4(6.3)$ & $1(1.6)$ & & & \\
\hline ATA recurrence risk & & & & $<.001$ & .014 & .344 \\
\hline Low risk & 237 (98.3) & $2(0.8)$ & $2(0.8)$ & & & \\
\hline Intermediate risk & $354(98.9)$ & $2(0.6)$ & $2(0.6)$ & & & \\
\hline High risk & $113(90.4)$ & $12(9.6)$ & 0 & & & \\
\hline AJCC cancer staging, 8th edition & & & & .065 & $>.99$ & $>.99$ \\
\hline Stage $1 / \|$ & $702(97.4)$ & $15(2.1)$ & $4(0.6)$ & & & \\
\hline Stage III/IV & $2(66.7)$ & $1(33.3)$ & 0 & & & \\
\hline BRAF V600E mutation & & & & .489 & $>.99$ & $>.99$ \\
\hline Absent & $107(99.1)$ & $1(0.9)$ & 0 & & & \\
\hline Present & $597(96.9)$ & $15(2.4)$ & $4(0.6)$ & & & \\
\hline
\end{tabular}

TERT, telomerase reverse transcriptase; TCF, tall cell features; ATA, American Thyroid Association; AJCC, American Joint Committee on Cancer. ${ }^{a}$ Classic papillary thyroid carcinoma (PTC) included classic PTC $(n=490)$, classic PTC with tall cell features $(n=83)$ and encapsulated classic PTC ( $\left.n=46\right) ;{ }^{b}$ Follicular variant included infiltrative follicular variant $(n=10)$ and invasive encapsulated follicular variant $(n=6)$; ' Other variants included 15 Warthin-like variant, 8 diffuse sclerosing variant, 8 oncocytic variant, 5 solid variant, 3 hobnail variant, and 1 cribriform-morular variant; alncluded both microscopic and gross extrathyroidal extension.

extrathyroidal extension was found in only 41 patients $(5.7 \%)$. No case developed synchronous distant metastasis. Therefore, it stands to reason that the vast majority $(86.0 \%)$ of patients with PTC were assigned to stage I by the 8th edition of the AJCC staging system. Although BRAF V600E mutations were highly prevalent in our study cohort, the frequency of hotspot mutations in the TERT promoter was $2.2 \%$, which is far lower than that reported in previous studies for PTC (pooled mean preva- lence of 11.3\%) [14,23]. These results indicate that most PTC tumors in the current study should have indolent behavior.

In our study, additional benefits were gained by including microcarcinomas in the molecular analysis. Hotspot mutations of the TERT promoter were found in five of 518 papillary microcarcinomas (1.0\%). Minimal extrathyroidal extension, found in three of the five patients with hotspot mutations, did not affect the pathologic T category. Patient age ranged from 39 to 84 


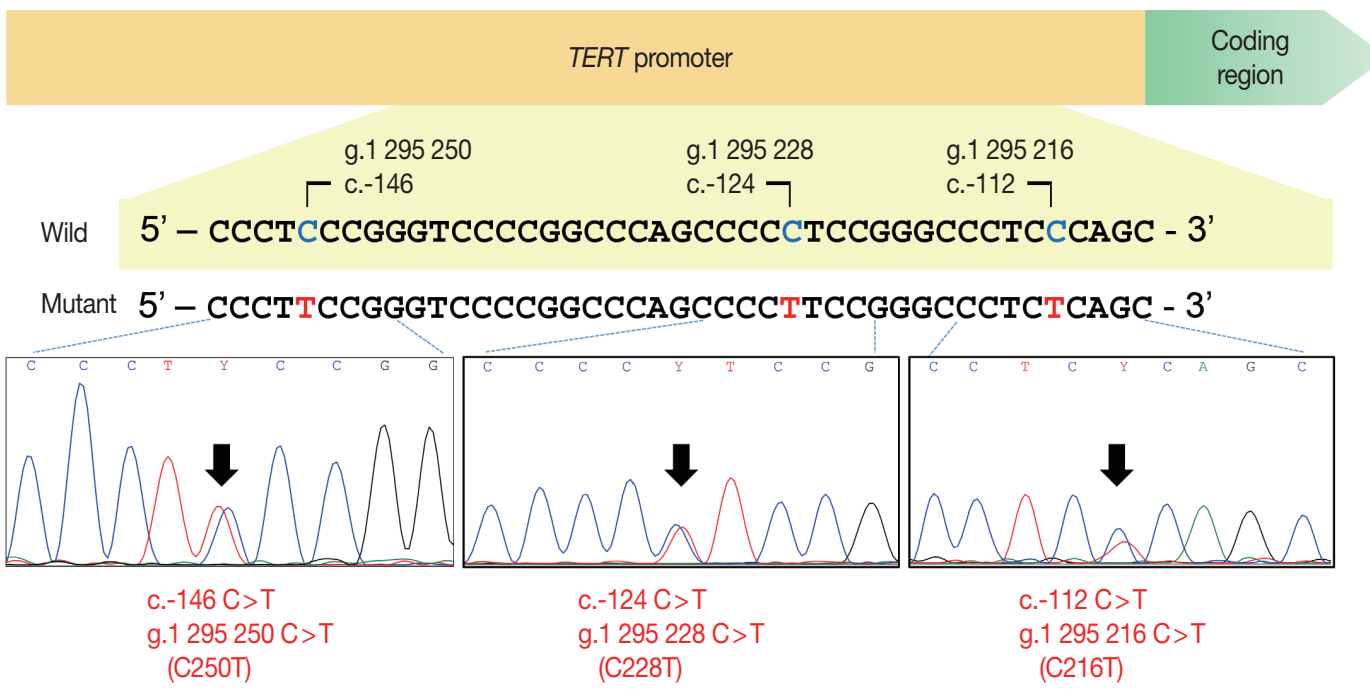

Fig. 1. Schematic figure of the telomerase reverse transcriptase (TERT) promoter region and sequencing electropherograms of two hotspot mutations (C228T and C250T) and a C216T variant in the TERT promoter. The hotspot mutations resulted from a cytosine-to-thymine transition at genomic loci Chr5:1,295,228 (C228T) and 1,295,250 (C250T), respectively. The C216T variant is a cytosine-to-thymine transition at the 1,295,216 position of Chr5.

Table 3. Clinicopathologic features of papillary thyroid carcinoma patients with TERT promoter alterations

\begin{tabular}{|c|c|c|c|c|c|c|c|c|c|c|c|c|c|}
\hline $\begin{array}{l}\text { Case } \\
\text { No. }\end{array}$ & $\begin{array}{l}\text { Age } \\
\text { (yr) }\end{array}$ & Sex & Surgery & $\begin{array}{c}\text { Tumor } \\
\text { size }(\mathrm{cm})\end{array}$ & Variant & $\begin{array}{l}\text { Multi- } \\
\text { focality }\end{array}$ & ETE & pT & $\mathrm{pN}$ & M & Stage & $\begin{array}{c}\text { TERT } \\
\text { promoter }\end{array}$ & $B R A F$ \\
\hline 1 & 77 & $F$ & Isthmusectomy & 0.3 & Classic & $\mathrm{N}$ & Absent & $1 a$ & 0 & 0 & 1 & C250T & Wild \\
\hline 2 & 60 & $\mathrm{~F}$ & Total lobectomy & 0.5 & Classic, encapsulated & Y & Absent & $1 a$ & 0 & 0 & 1 & C250T & V600E \\
\hline 3 & 55 & $\mathrm{~F}$ & Lobectomy & 0.8 & Classic & Y & Microscopic & $1 a$ & 0 & 0 & 1 & C228T & V600E \\
\hline 4 & 46 & $\mathrm{~F}$ & Total lobectomy & 1.5 & Classic & Y & Microscopic & $1 b$ & 0 & 0 & 1 & C228T & V600E \\
\hline 5 & 66 & $\mathrm{~F}$ & Total lobectomy & 2.0 & Classic & Y & Strap muscle invasion & $3 b$ & 0 & 0 & 2 & C228T & V600E \\
\hline 6 & 57 & M & Total lobectomy & 2.6 & Classic & $\mathrm{N}$ & Strap muscle invasion & $3 b$ & $1 b$ & 0 & 2 & C228T & V600E \\
\hline 7 & 68 & M & Lobectomy & 2.8 & Classic & Y & Microscopic & 2 & 0 & 0 & 1 & C228T & V600E \\
\hline 8 & 60 & $\mathrm{~F}$ & Lobectomy & 0.7 & Classic with TCF & Y & Microscopic & $1 a$ & 0 & 0 & 1 & C228T & V600E \\
\hline 9 & 76 & F & Total lobectomy & 1.3 & Classic with TCF & Y & Microscopic & $1 b$ & $1 a$ & 0 & 2 & C228T & V600E \\
\hline 10 & 59 & $\mathrm{~F}$ & Total lobectomy & 1.6 & Classic with TCF & $\mathrm{N}$ & Microscopic & $1 b$ & 0 & 0 & 1 & C228T & V600E \\
\hline 11 & 39 & $\mathrm{~F}$ & Total lobectomy & 2.1 & Classic with TCF & $\mathrm{N}$ & Microscopic & 2 & $1 b$ & 0 & 1 & C228T & V600E \\
\hline 12 & 65 & M & Total lobectomy & 3.2 & Classic with TCF & Y & Strap muscle invasion & $3 b$ & $1 a$ & 0 & 2 & C228T & V600E \\
\hline 13 & 75 & $\mathrm{~F}$ & Total lobectomy & 2.0 & Tall cell & $\mathrm{N}$ & Strap muscle invasion & $3 b$ & $1 a$ & 0 & 2 & C228T & V600E \\
\hline 14 & 74 & M & Lobectomy & 2.7 & Tall cell & $\mathrm{N}$ & Strap muscle invasion & $3 b$ & 0 & 0 & 2 & C228T & V600E \\
\hline 15 & 84 & $\mathrm{~F}$ & Total lobectomy & 5.5 & Tall cell & $\mathrm{N}$ & Esophagus invasion & $4 a$ & $1 b$ & 0 & 3 & C228T & V600E \\
\hline 16 & 64 & M & Total lobectomy & 0.7 & Oncocytic & Y & Microscopic & $1 \mathrm{a}$ & $1 b$ & 0 & 2 & С228T & V600E \\
\hline 17 & 44 & $\mathrm{~F}$ & Lobectomy & 0.4 & Classic & $\mathrm{N}$ & Absent & $1 a$ & 0 & 0 & 1 & C216T & V600E \\
\hline 18 & 55 & $F$ & Total lobectomy & 0.5 & Classic & $\mathrm{N}$ & Absent & $1 \mathrm{a}$ & 0 & 0 & 1 & $\mathrm{C} 216 \mathrm{~T}$ & V600E \\
\hline 19 & 29 & M & Total lobectomy & 1.0 & Classic & Y & Microscopic & $1 a$ & $1 b$ & 0 & 1 & $\mathrm{C} 216 \mathrm{~T}$ & V600E \\
\hline 20 & 54 & $\mathrm{M}$ & Lobectomy & 1.2 & Classic & $\mathrm{N}$ & Microscopic & $1 \mathrm{~b}$ & 0 & 0 & 1 & $\mathrm{C} 216 \mathrm{~T}$ & V600E \\
\hline
\end{tabular}

TERT, telomerase reverse transcriptase; ETE, extrathyroidal extension; F, female; M, male; Y, yes; N, no; TCF, tall cell features.

years. Although the frequency of TERT promoter mutations is lower than that of previous studies, these findings are in line with a previous Italian study showing no correlation with unfavorable outcomes [24]. The Italian study showed that TERT promoter mutations were found in $4.7 \%$ of papillary microcarcinomas and were not associated with poor clinical features [24]. As active surveillance is one of the treatment options for low-risk papillary microcarcinomas, the identification of TERT promoter mutations may facilitate decision-making on appropriate candidates for active surveillance $[21,25]$. One Japanese study reported that no TERT promoter mutations were found in 25 patients selected from 1,252 patients with low-risk papillary microcarcinoma who were managed with active surveillance [25]. These results, however, need to be validated in further larger studies. 


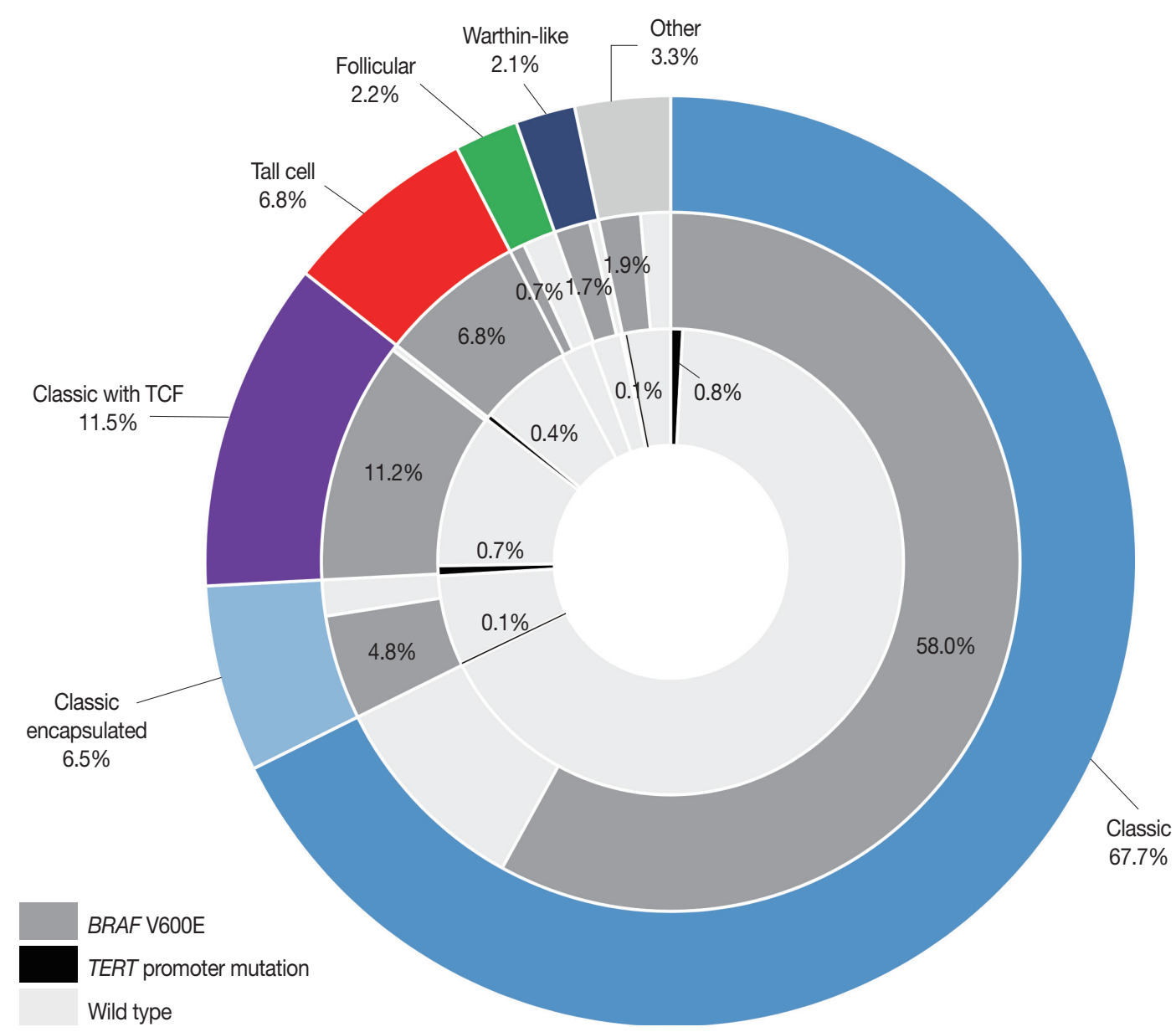

Fig. 2. A pie chart depicting a portion of BRAF V600E and telomerase reverse transcriptase (TERT) promoter mutations (C228T and C250T) in relation to histologic variants of papillary thyroid carcinoma $(n=724)$. The middle and inner circles show the frequency of $B R A F V 600 E$ and TERT promoter mutations, respectively. The other variants included eight diffuse sclerosing, eight oncocytic, five solid, three hobnail, and one cribriform-morular variant. TCF, tall cell features.

Since most studies reported only pathogenic hotspot mutations, little is known about the prevalence and functional role of the TERT promoter $\mathrm{C} 216 \mathrm{~T}$ variant in human cancers. The $\mathrm{C} 216 \mathrm{~T}$ variant was found in four cases of our study cohort and has been previously reported in two lung adenocarcinomas [26] and one esophageal squamous cell carcinoma [27]. In our study, all four patients with the C216T were younger (range, 29 to 55 years) than those with hotspot mutations and had no unfavorable clinicopathologic features. Therefore, we suggest that the TERT promoter C216T variant may be a non-pathogenic DNA polymorphism in PTC.

Many studies have shown synergistic effects of concurrent $B R A F$ V600E and TERT promoter mutations on the poor prognosis and mortality risk of patients with PTC $[8,11,17-19,23]$. The C228T and C250T mutations of the TERT promoter generate an 11-bp binding motif (5'-CCCCTTCCGGG-3') for E-twenty- six (ETS) transcription factors [13]. Mitogen-activated protein kinase pathway activation by the BRAF V600E mutation upregulates ETS transcription factors, which results in increased TERT mRNA expression by the binding of the mutated TERT promoter to ETS [28]. In our study, all 14 patients with the TERT promoter C228T mutation had a concurrent BRAF V600E mutation. In Korean patients with PTC and a high prevalence of the BRAF V600E, further studies are needed to validate the prognostic utility of risk stratification of patients with PTC by combining BRAF V600E and TERT promoter mutations.

In summary, this study demonstrated that the TERT promoter mutation frequency was $2.2 \%$ in prospectively collected patients, and the presently reported frequency is lower than that reported in previous studies. TERT promoter mutations were more common in older patients with unfavorable clinicopathologic fea- 
tures and a BRAF V600E mutation. Although they were observed less frequently than in those with larger tumors, TERT promoter mutations also occurred in patients with microcarcinoma and lowrisk clinicopathologic features. The $\mathrm{C} 216 \mathrm{~T}$ variant was found in $0.6 \%$ of all PTCs and may be a non-pathogenic DNA polymorphism.

\section{Ethics Statement}

This study was approved by the Institutional Review Board of Seoul St. Mary's Hospital, the Catholic University of Korea (KC16SISI0709). Informed consent was obtained from each patient.

\section{ORCID}

Sue Youn Kim https://orcid.org/0000-0003-0279-9787

Taeeun Kim https://orcid.org/0000-0001-6945-8616

Kwangsoon Kim https://orcid.org/0000-0001-6403-6035

Ja Seong Bae https://orcid.org/0000-0002-6271-2105

Jeong Soo Kim https://orcid.org/0000-0002-9982-7838

Chan Kwon Jung https://orcid.org/0000-0001-6843-3708

\section{Author Contributions}

Conceptualization: CKJ. Data curation: SYK, TK, KK, JSB, JSK, CKJ. Formal analysis: SYK, TK, CKJ. Funding acquisition: CKJ. Investigation: SYK, TK, CKJ. Methodology: SYK, TK, CKJ. Project administration: SYK, CKJ. Resources: SYK, KK, JSB, JSK, CKJ. Software: SYK, CKJ. Supervision: CKJ. Validation: KK, JSB, JSK, CKJ. Visualization: SYK, KK, JSB, JSK, CKJ. Writing—original draft: SYK, CKJ. Writing_review \& editing: SYK, TK, KK, JSB, JSK, CKJ. Approval of final manuscript: all authors.

\section{Conflicts of Interest}

C.K.J. is the editor-in-chief of the Journal of Pathology and Translational Medicine and was not involved in the editorial evaluation or decision to publish this article. All remaining authors declare that they have no potential conflicts of interest.

\section{Funding Statement}

This study was supported by a grant (2017R1D1A1B03029597) from the Basic Science Research Program through the National Research Foundation of Korea.

\section{References}

1. Vaccarella S, Franceschi S, Bray F, Wild CP, Plummer M, Dal Maso L. Worldwide thyroid-cancer epidemic? The increasing impact of overdiagnosis. N Engl J Med 2016; 375: 614-7.

2. Ahn HS, Kim HJ, Kim KH, et al. Thyroid cancer screening in South Korea increases detection of papillary cancers with no impact on other subtypes or thyroid cancer mortality. Thyroid 2016; 26: 1535-40.

3. Ahn HS, Kim HJ, Welch HG. Korea's thyroid-cancer "epidemic": screening and overdiagnosis. N Engl J Med 2014; 371: 1765-7.

4. Jung KW, Won YJ, Kong HJ, Lee ES. Cancer statistics in Korea: incidence, mortality, survival, and prevalence in 2016. Cancer Res Treat 2019; 51: 417-30.

5. Park S, Oh CM, Cho H, et al. Association between screening and the thyroid cancer "epidemic" in South Korea: evidence from a nationwide study. BMJ 2016; 355: i5745.

6. Jeon MJ, Kim WG, Kim TH, et al. Disease-specific mortality of differentiated thyroid cancer patients in Korea: a multicenter cohort study. Endocrinol Metab (Seoul) 2017; 32: 434-41.

7. Lloyd RV, Osamura RY, Klöppel G, Rosai J. WHO classification of tumours of endocrine organs. 4th ed. Lyon: International Agency for Research on Cancer (IARC), 2017; 65-91.

8. Liu R, Bishop J, Zhu G, Zhang T, Ladenson PW, Xing M. Mortality risk stratification by combining BRAF V600E and TERT promoter mutations in papillary thyroid cancer: genetic duet of BRAF and TERT promoter mutations in thyroid cancer mortality. JAMA Oncol 2017; 3: 202-8.

9. Kim TH, Kim YE, Ahn S, et al. TERT promoter mutations and long-term survival in patients with thyroid cancer. Endocr Relat Cancer 2016; 23: 813-23.

10. Liu X, Qu S, Liu R, et al. TERT promoter mutations and their association with BRAF V600E mutation and aggressive clinicopathological characteristics of thyroid cancer. J Clin Endocrinol Metab 2014; 99: E1130-6.

11. Melo M, da Rocha AG, Vinagre J, et al. TERT promoter mutations are a major indicator of poor outcome in differentiated thyroid carcinomas. J Clin Endocrinol Metab 2014; 99: E754-65.

12. Horn S, Figl A, Rachakonda PS, et al. TERT promoter mutations in familial and sporadic melanoma. Science 2013; 339: 959-61.

13. Huang FW, Hodis E, Xu MJ, Kryukov GV, Chin L, Garraway LA. Highly recurrent TERT promoter mutations in human melanoma. Science 2013; 339: 957-9.

14. Bae JS, Kim Y, Jeon S, et al. Clinical utility of TERT promoter mutations and $A L K$ rearrangement in thyroid cancer patients with a high prevalence of the BRAF V600E mutation. Diagn Pathol 2016; 11: 21 .

15. Xing M, Liu R, Liu X, et al. BRAF V600E and TERT promoter mutations cooperatively identify the most aggressive papillary thyroid cancer with highest recurrence. J Clin Oncol 2014; 32: 2718-26.

16. Jung CK, Kim Y, Jeon S, Jo K, Lee S, Bae JS. Clinical utility of EZH1 mutations in the diagnosis of follicular-patterned thyroid tumors. Hum Pathol 2018; 81: 9-17.

17. Landa I, Ganly I, Chan TA, et al. Frequent somatic TERT promoter mutations in thyroid cancer: higher prevalence in advanced forms of the disease. J Clin Endocrinol Metab 2013; 98: E1562-6.

18. Liu X, Bishop J, Shan Y, et al. Highly prevalent TERT promoter mutations in aggressive thyroid cancers. Endocr Relat Cancer 2013; 20: 603-10.

19. Song YS, Lim JA, Choi H, et al. Prognostic effects of TERT promoter mutations are enhanced by coexistence with BRAF or RAS mutations and strengthen the risk prediction by the ATA or TNM staging system in differentiated thyroid cancer patients. Cancer 2016; 122: 1370-9.

20. Amin MB, Edge S, Greene F, et al. AJCC cancer staging manual. 8th ed. New York: Springer, 2017; 873-90.

21. Haugen BR, Alexander EK, Bible KC, et al. 2015 American Thyroid Association management guidelines for adult patients with thyroid nodules and differentiated thyroid cancer: the American Thyroid Association Guidelines Task Force on Thyroid Nodules and Differentiated Thyroid Cancer. Thyroid 2016; 26: 1-133.

22. Jeong D, Jeong Y, Lee $\mathrm{S}$, et al. Detection of $B R A F(\mathrm{~V} 600 \mathrm{E})$ mutations in papillary thyroid carcinomas by peptide nucleic acid clamp real-time PCR: a comparison with direct sequencing. Korean J Pathol 2012; 46: 61-7.

23. Yang J, Gong Y, Yan S, Chen H, Qin S, Gong R. Association between TERT promoter mutations and clinical behaviors in differ- 
entiated thyroid carcinoma: a systematic review and meta-analysis. Endocrine 2020; 67: 44-57.

24. de Biase D, Gandolfi G, Ragazzi M, et al. TERT promoter mutations in papillary thyroid microcarcinomas. Thyroid 2015; 25: 1013-9.

25. Yabuta T, Matsuse M, Hirokawa M, Yamashita S, Mitsutake N, Miyauchi A. TERT promoter mutations were not found in papillary thyroid microcarcinomas that showed disease progression on active surveillance. Thyroid 2017; 27: 1206-7.
26. Ma X, Gong R, Wang R, et al. Recurrent TERT promoter mutations in non-small cell lung cancers. Lung Cancer 2014; 86: 369-73.

27. Zhao Y, Gao Y, Chen Z, Hu X, Zhou F, He J. Low frequency of TERT promoter somatic mutation in 313 sporadic esophageal squamous cell carcinomas. Int J Cancer 2014; 134: 493-4.

28. Song YS, Yoo SK, Kim HH, et al. Interaction of BRAF-induced ETS factors with mutant TERT promoter in papillary thyroid cancer. Endocr Relat Cancer 2019; 26: 629-41. 